\title{
Identifying Poor Adherence in Outpatients with Bipolar Disorder: A Comparison of Different Measures
}

\author{
Nidhi Chauhan ${ }^{1,2}$ Subho Chakrabarti ${ }^{1}$ Sandeep Grover ${ }^{1}$ \\ ${ }^{1}$ Department of Psychiatry, Postgraduate Institution of Medical \\ Education and Research (PGIMER), Chandigarh, India \\ ${ }^{2}$ Department of Psychiatry, Government Medical College and \\ Hospital, Chandigarh, India
}

\begin{abstract}
Address for correspondence Subho Chakrabarti, MD, FRCPsych, Department of Psychiatry, Postgraduate Institution of Medical Education and Research (PGIMER), Sector 12, Chandigarh 160012, India (e-mail: subhochd@yahoo.com).
\end{abstract}

J Neurosci Rural Pract 2022;13:12-22.

\begin{abstract}
Keywords

- bipolar disorder

- outpatients

- inadequate adherence

- detection

- measures
\end{abstract}

Objective Unlike schizophrenia, comparisons of different methods of estimating inadequate adherence in bipolar disorder (BD) are scarce. This study compared four methods of identifying inadequate adherence among outpatients with BD.

Materials and Methods Two self-reports, the Morisky Medication Adherence Questionnaire (MAQ) and the Drug Attitude Inventory (DAI-10), clinician ratings employing the Compliance Rating Scale (CRS), mood-stabilizer levels, and clinic-based pill counts were compared at intake in 106 outpatients with BD and after 6 months of follow-up $(n=75)$. Statistical Analysis Rates of nonadherence were determined for each method. The ability to detect inadequate adherence was based on sensitivity, specificity, positive and negative predictive values (PPV and NPV), and positive and negative likelihood ratios (LR positive and LR negative). Correlation coefficients and Cohen's kappa values were used to determine the agreement between measures. Correlation coefficients were also used to evaluate the determinants of inadequate adherence

Results The MAQ and the DAl-10 (cut-off score of two) yielded higher rates of nonadherence $(35-47 \%)$ than the other methods. They were better at detecting adherence (specificity, 34-42\%; PPV, 40-44\%; and LR negative, $0.70-0.96$ ) than other measures and had moderate ability to identify nonadherence compared with them (sensitivity, 63-73\%; NPV, 54-70\%; and LR positive, 1.02-1.16). They were associated with several established predictors of nonadherence. The MAQ and DAI-10 scores and the MAQ and CRS scores were modestly correlated. Multivariate analysis showed that $20 \%$ of the variance in the DAI- 10 scores was explained by the MAQ scores. Despite their low yield, serum levels had a high sensitivity (88\%) and higher accuracy (55\%) in identifying inadequate adherence. CRS ratings and pill counts had high sensitivity but low specificity to detect inadequate adherence.

Conclusion Self-reports appeared to be the most efficient method of ascertaining inadequate adherence among outpatients with BD. However, since none of the measures were adequate by themselves, a combination of different measures is more likely to maximize the chances of identifying inadequate adherence among these patients. published online September 28, 2021
DOI https://doi.org/ 10.1055/s-0041-1736155. ISSN 0976-3147.

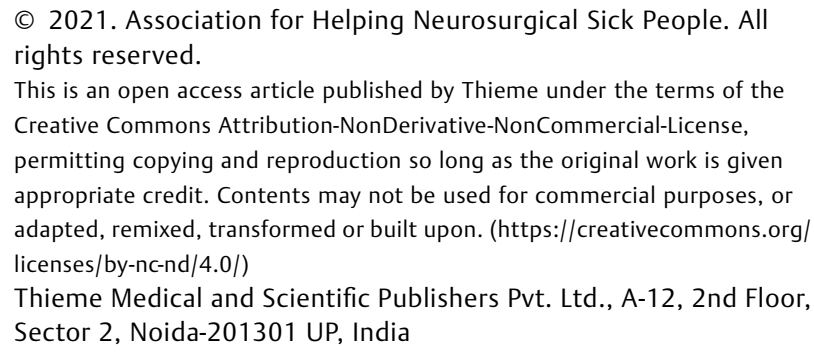

(C) 2021. Association for Helping Neurosurgical Sick People. All rights reserved.

This is an open access article published by Thieme under the terms of the Creative Commons Attribution-NonDerivative-NonCommercial-License, permitting copying and reproduction so long as the original work is given appropriate credit. Contents may not be used for commercial purposes, or adapted, remixed, transformed or built upon. (https://creativecommons.org/ licenses/by-nc-nd/4.0/) Thieme Medical and Scientific Publishers Pvt. Ltd., A-12, 2nd Floor, Sector 2, Noida-201301 UP, India 


\section{Introduction}

About half of the patients with bipolar disorder (BD) do not take their medications properly. ${ }^{1,2}$ Failure to recognize nonadherence perpetuates its undesirable clinical and socioeconomic consequences among these patients. ${ }^{2,3}$ However, there is no single measure which accurately identifies nonadherence. ${ }^{3,4}$ Different methods to detect nonadherence in BD have included subjective measures such as patients' reports and clinicians' judgments, as well as objective ones including serum levels, pill counts, medication event monitoring systems, and pharmacy refill records. ${ }^{1,4,5}$ Many of these measures have been used only in research settings. Their findings may not apply to busy and resource-constrained clinical settings. ${ }^{6}$ In routine practice adherence measures need to be brief, simple, relatively unobtrusive, and reasonably accurate. Though objective methods may be more accurate, they are often expensive and not readily available. Therefore, self-reports are considered more suitable for clinical settings. However, the utility of self-reports is often undermined by patients' tendencies to inflate adherence because of biased recall, pressures to conform, and impaired insight or cognition in BD. ${ }^{1,2,5}$ Although correlations with other measures are generally high, ${ }^{1,5}$ low concordances has also been reported in $\mathrm{BD} .{ }^{7,8}$ Among objective measures, mood-stabilizer levels are frequently used in clinical settings, because they are relatively more accessible and correlate well with other methods. ${ }^{1,5}$

Though several studies have used multiple measures to evaluate nonadherence among outpatients with $\mathrm{BD}$, very few have compared the relative usefulness of the different measures, especially on parameters such as sensitivity, specificity, or concordance. ${ }^{5,9-11}$ Many of these studies have methodological shortcomings including variable sample sizes, crosssectional designs, lack of validated self-reports, and samples drawn from specialty clinics or medication trials. Thus, this study compared the relative utility of four different subjective and objective methods in identifying nonadherence among outpatients with BD from a hospital-based service. The measures selected were validated self-reports and clinician-rated scales, mood-stabilizer levels, and pill counts. Prospective follow-up was performed to account for variations in adherence over time. ${ }^{5}$ The four measures were compared on their ability to detect inadequate adherence, the extent of inadequate adherence detected, their association with the determinants of nonadherence, and the agreement between them.

\section{Materials and Methods}

\section{Patients and Caregivers}

Adult patients ( $<65$ years) with BD diagnosed according to the Diagnostic and Statistical Manual of Mental Disorders, 4th edition, who had been ill for at least a year and had developed at least two episodes, were inducted. Exclusion criteria included learning disability and BD secondary to physical illnesses or alcohol/drug abuse. Those at risk of harm to themselves or others were not included. Adult family members of these patients were included if they had no psychiatric illnesses and were involved in the patient's care for at least a year. A total of 123 patient-caregiver pairs met the requirements but only 106 of them could be assessed. Baseline assessments covered 3 months before inclusion. Prospective assessments were performed at 3 and 6 monthly visits. About $30 \%$ of the patients $(n=31)$ stopped attending by the first 3 months of follow-up. Thus, 75 patients and caregivers were available for assessment at 3 and 6 months. The protocol was approved by the institutional review board. Participants gave informed consent in writing before taking part. Other ethical principles were adhered to during the study.

\section{Clinical Evaluations}

The Mini-International Neuropsychiatric Interview was employed to establish valid diagnoses. The severity of symptoms was evaluated by the Hamilton Depression Rating Scale (HDRS) and the Young Mania Rating Scale (YMRS), and functional impairment by the Global Assessment of Functioning scale (GAF) for the preceding 3 months during all the assessments. $^{12}$

\section{Adherence Evaluations}

A Hindi translation of the four-item Morisky Medication Adherence Questionnaire (MAQ) was used to evaluate selfreported adherence for 3 months before each evaluation. ${ }^{13}$ Clinicians rated adherence on the Compliance Rating Scale (CRS). ${ }^{14}$ High scores on both these scales denote greater adherence. Patients were also classified as adherent (MAQ score: $3,4 / C R S \geq 5$ ) or poorly adherent (MAQ score: $0,1,2$ / $\mathrm{CRS} \leq 4)$. Attitudes toward medications and adherence were both evaluated by the Drug Attitude Inventory, 10-item version (DAI-10). ${ }^{15}$ Elevated scores on the DAI-10 signify favorable views of medications. A positive difference (scores $>0$ ) between the total negative-item score and the positiveitem score represents adherence on this scale. Outpatientbased pill counts were performed by asking caregivers to preserve and bring all medication strips that patients had used for 3 months. Patients consuming less than $80 \%$ of their recommend medications were categorized as inadequately adherent. Average mood-stabilizer levels over the prior 3 months were also calculated. Patients with serum lithium levels less than $0.5 \mathrm{mEq} / \mathrm{L}$ and valproate levels less than $50 \mu \mathrm{g} / \mathrm{mL}$ were rated as being poorly adherent.

\section{Evaluation of Determinants of Inadequate Adherence} The Scale to Assess Unawareness of Mental Disorder (SUMD) ${ }^{16}$ was used to rate patients' insight. Elevated scores on this scale denote a lack of insight. The Udvalg for Kliniske Undersogelser Side Effect Rating Scale (UKU) ${ }^{12}$ was employed to evaluate adverse effects. Patients' and caregivers' knowledge about BD was rated using a modified scale composed of five items. ${ }^{17}$ Patients' and caregivers' attitudes toward medications were further evaluated using the 18-item Self-Reported Attitudes toward Psychotropic Medications Questionnaire (SRAQ). ${ }^{18}$ Positive views about medications on this scale are indicated by elevated scores of all items, as well as positive and negative 
items. Satisfaction with treatment was rated with the fouritem Patient Satisfaction Questionnaire (PSQ) among patients. ${ }^{19}$ The content of the PSQ was minimally altered to assess caregivers' satisfaction. Greater scores on this scale signify greater satisfaction.

\section{Statistical Analysis}

Participants' profiles and rates of inadequate adherence between evaluations at intake and completion were compared using appropriate parametric and nonparametric tests. Sensitivity, specificity, positive and negative predictive values (PPV and NPV), positive and negative likelihood ratios (LR positive and LR negative), and classification accuracy were estimated for all the measured adherence measures employing the MAQ as the standard. Correlation coefficients and Cohen's kappa values were used to determine agreement/concordance among the four measures. Univariate analysis of the relationship between poor adherence and its determinants was evaluated by correlational analysis. Stepwise multiple regression analyses were also to further evaluate these relationships.

\section{Results}

Results were available for three assessments, at intake and at 3 and 6 months. Results of the evaluations at 3- and 6-month assessments were more or less the same. Therefore, only the results for intake and 6-month evaluations have been analyzed.

\section{Participants}

Patients were mostly middle-aged men, married and employed with approximately 12 years of schooling (-Table 1). The majority came from low-income, middleclass families. Patients' profiles at baseline and final assessments were compared with determine the impact of the 31 dropouts in the first 3 months. Significant differences that emerged included younger age, lower age of onset, longer duration, and greater severity of depressive and mixed episodes among patients at the final assessment. Therefore, patients who dropped out influenced the make-up of the 6-month samples to an extent but not substantially. Longitudinal profiles indicated a benign course of illness among patients over 10 years with an average of five moderately severe episodes, each for about 3 months. Symptom scores and levels of functioning suggested that patients were in remission when assessed. The YMRS scores declined significantly over 6 months. Additionally, the GAF scores increased, but this change fell just short of significance. Depressive symptoms, insight, and knowledge of illness among patients also improved but not significantly. Family members of patients were their wives/husbands or fathers/mothers. Their average age and educational levels were higher, and they were more often married and working. However, caregivers did not differ significantly from patients in their attitudes toward medications, satisfaction with treatment, or knowledge of the disorder. No significant differences were observed in these parameters either among patients or their caregivers during follow-up.

\section{Rates of Inadequate Adherence}

At baseline, the maximum rate of inadequate adherence (47\%) was obtained with the MAQ categories (-Table 2 ). This rate was significantly higher than those obtained with the CRS categorization, the DAI-10 categories with a cut-off score of 0 , pill counts, and mood-stabilizer levels. Since certain studies have indicated that scores of one or higher are more suitable cut-offs on the DAI- $10,{ }^{20,21}$ DAI- 10 categories with a cut-off score of 2 were also estimated. Nonadherence rates were higher (35\%) with this cut-off and not significantly different from the MAQ categorization. Though rates of nonadherence declined over 6 months (except in the case of the DAI-10 with higher cut-off), none of these reductions were significant concerning the MAQ CRS, or the DAI-10 score, the proportions of medications consumed and average serum levels. The proportion of poorly adherent patients generated by the four methods was not significantly different during the period of the study. However, most of the patients who had dropped out (30\%) had discontinued medications. Consequently, there was a slight increase in the composite rate of nonadherence from the baseline (20\%) to the final assessment (23\%).

\section{Psychometric Properties of Adherence Measures}

High sensitivity, along with high NPVs, and LR positive $>1$, all indicate greater ability to identify patients with nonadherence. $^{20-22}$ On the other hand, high specificity, high PPVs, and LR negative approximating 1 signify greater ability to detect adherence. According to these parameters, the MAQ and the DAI-10 (with higher cut-off) were better at detecting adherence (specificity, 34-42\%; PPVs, 40-44\%; and LR negative, 0.70-0.96) than the other measures and had moderate ability to identify nonadherence compared with them (sensitivity, 63-73\%; NPVs, 54-70\%; and LR positive, 1.02-1.16). Since its sensitivity and specificity in detecting nonadherence are well established, ${ }^{22}$ the MAQ was chosen as the reference standard for the other measures. The CRS ratings and pill counts were good at detecting nonadherence, but poor at detecting adherent patients and often falsely identified them as nonadherent. Moreover, all these four measures could correctly classify only half of the patients as either adherent or nonadherent. In contrast, despite their low yields, mood-stabilizer levels had high sensitivity (88\%) and higher accuracy (55\%) in identifying nonadherence, together with a reasonably high ability to detect adherence (moderately high specificity and PPV).

\section{Correlates of Adherence Measures}

Univariate analysis showed that approximately $80 \%$ of the determinants of adherence were common to all the adherence measures evaluated (-Tables 3 and $\mathbf{4}$ ). Overall, caregivers' knowledge of the illness including knowledge of diagnosis, treatment, and causes, and patient's knowledge of the illness including knowledge about symptoms and diagnosis emerged as the principal correlates of adherence. Impaired insight, patients' attitudes and their treatment satisfaction also proved to be important determinants. However, clinical variables, including the YMRS scores and 
Table 1 Profile of the study sample

\begin{tabular}{|c|c|c|}
\hline Demographics & Baseline assessment $(n=106)$ & Final assessment $(n=75)$ \\
\hline Age $(y)^{a}$ & $38(12.4)^{\mathrm{b}}$ & $34(12.3)^{\mathrm{e}}$ \\
\hline Gender (male/female) & $79 / 27$ & $52 / 23$ \\
\hline Marital status (Married/Single) & $82 / 24$ & $59 / 16$ \\
\hline Education (y) & $12.1(3.8)$ & $12(3.7)$ \\
\hline Occupation ( $n$; employed/unemployed) & $102 / 4$ & $71 / 4$ \\
\hline Family income (rupees/mo) & $13,074(11,963)$ & $12,871(12,538)$ \\
\hline Family type (nuclear/nonnuclear) & $67 / 39$ & $47 / 28$ \\
\hline Residence (urban/rural) & $66 / 40$ & $46 / 29$ \\
\hline Socioeconomic class ( $n$; middle/others) & $61 / 45$ & $41 / 34$ \\
\hline Socioeconomic status scores & $16.8(5.8)$ & $16(5.75)$ \\
\hline Age of onset $(y)^{a}$ & $28(9.7)$ & $24(9.7)^{f}$ \\
\hline Illness duration of (mo) & $122.4(111.9)$ & $122(112.1)$ \\
\hline Treatment duration (mo) & $61.1(85.9)$ & $72(95)$ \\
\hline \multicolumn{3}{|l|}{ Lifetime episodes } \\
\hline Manic/hypomanic & $3(2.9)$ & $2.9(2.7)$ \\
\hline Depressive & $1.8(2.4)$ & $2.0(2.7)$ \\
\hline Mixed & $0.1(0.6)$ & $0.1(0.6)$ \\
\hline \multicolumn{3}{|l|}{ Episode duration (mo) } \\
\hline Manic/hypomanic & $1.68(1.32)$ & $1.6(1.4)$ \\
\hline Depressive & $1.54(1.13)$ & $2.0(0.9)^{f}$ \\
\hline Mixed & $0.29(1.4)$ & $2.2(1.1)^{g}$ \\
\hline \multicolumn{3}{|l|}{ Episode severity ${ }^{\mathrm{a}, \mathrm{c}}$} \\
\hline Manic/hypomanic & $2.2(0.6)$ & $2.1(0.5)$ \\
\hline Depressive & $1.6(1.1)$ & $2.3(0.5)^{g}$ \\
\hline Mixed & $0.3(1.5)$ & $2.5(0.7)^{g}$ \\
\hline Affective morbidity index scores ${ }^{d}$ & $22(20.7)$ & $20.2(20.2)$ \\
\hline Comorbid substance use disorders & 37 & 20 \\
\hline Comorbid medical disorders & 26 & 28 \\
\hline YMRS scores & $2.4(6.0)$ & $0.8(2.3)^{\mathrm{e}}$ \\
\hline HDRS scores & $2.2(5.2)$ & $1.8(4.0)$ \\
\hline GAF scores & $71.3(15.2)$ & $75.3(13.1)$ \\
\hline \multicolumn{3}{|l|}{ SUMD scores } \\
\hline Awareness of mental disorder & $1.8(1.2)$ & $1.7(1.1)$ \\
\hline Awareness of effects achieved by medication & $1.5(1.0)$ & $1.4(0.9)$ \\
\hline Awareness of social consequences of mental disorder & $1.6(1.1)$ & $1.5(1.0)$ \\
\hline Total SUMD scores & $5.1(3.1)$ & $4.7(2.7)$ \\
\hline Patients' knowledge about illness scores & $4.5(2.3)$ & $4.8(2.4)$ \\
\hline Mood stabilizers & $n=88$ & $n=65$ \\
\hline Lithium & 47 & 33 \\
\hline Valproate & 41 & 32 \\
\hline Mood stabilizer dose (mg/d) & $832(214) 1,001$ & $833(216)$ \\
\hline Lithium valproate & $(340)$ & $1,025(324)$ \\
\hline Average serum levels over past 3 months & & \\
\hline
\end{tabular}


Table 1 (Continued)

\begin{tabular}{|c|c|c|}
\hline Demographics & Baseline assessment $(n=106)$ & Final assessment $(n=75)$ \\
\hline Lithium (mmol/L) & 1.0 & 0.7 \\
\hline Valproate $(\mu \mathrm{g} / \mathrm{mL})$ & 67.5 & 70.3 \\
\hline Antipsychotics & 57 & 38 \\
\hline Antidepressants & 22 & 16 \\
\hline Benzodiazepines & 17 & \\
\hline Number of psychotropics & $3.4(1.8)$ & $3.4(1.9)$ \\
\hline Number of nonpsychotropics & $0.39(0.95)$ & $0.46(1.1)$ \\
\hline Number of all medications & $3.8(2.2)$ & $3.8(2.9)$ \\
\hline Number of side effects on the UKU & $3.6(3.1)$ & $3.8(3.1)$ \\
\hline \multicolumn{3}{|l|}{ Patients' SRAQ scores } \\
\hline Positive score & $19.9(3.2)$ & $20.1(3.4)$ \\
\hline Negative score & $22.3(4.0)$ & $22.4(4.3)$ \\
\hline Total score & $42.2(5.1)$ & $42.6(5.6)$ \\
\hline Patients' treatment satisfaction scores & $5.1(1.9)$ & $5.0(1.8)$ \\
\hline Caregivers' knowledge about illness scores & $4.1(2.1)$ & $4.2(2.1)$ \\
\hline \multicolumn{3}{|l|}{ Caregivers' SRAQ scores } \\
\hline Positive score & $20.2(2.4)$ & $20.3(2.5)$ \\
\hline Negative score & $22.2(3.4)$ & $22.5(3.4)$ \\
\hline Total score & $42.5(4.5)$ & $42.8(4.9)$ \\
\hline Caregivers' treatment satisfaction scores & $5.0(2.3)$ & $5.1(2.2)$ \\
\hline
\end{tabular}

Abbreviations: GAF, Global Assessment of Functioning scale; HDRS, Hamilton Depression Rating Scale; SRAQ, Self-Reported Attitudes Toward Psychotropic Medications Questionnaire; SUMD, Scale to Assess Unawareness of Mental Disorder; UKU, Udvalg for Kliniske Undersogelser Side Effect Rating Scale; YMRS, Young Mania Rating Scale.

${ }^{\mathrm{a} T h e s e ~ p a r a m e t e r s ~ w e r e ~ s i g n i f i c a n t l y ~ d i f f e r e n t ~ w h e n ~ i n t a k e ~ a n d ~ f i n a l ~ e v a l u a t i o n s ~ w e r e ~ c o m p a r e d ~(r e s u l t s ~ o f ~ t h e ~} t$ and Chi-square tests).

bFigures in brackets are standard deviations.

'Severity of mood episodes was graded as mild (1), moderate (2), and severe (3).

${ }^{\mathrm{d}}$ This measure of longitudinal severity reflected the frequency, duration, and severity of episodes.

eSignificantly different parameter, $p<0.05$ (results of the $t$ and Chi-square tests).

fSignificantly different parameter, $p<0.01$ (results of the $t$ and Chi-square tests).

${ }^{9}$ Significantly different parameter, $p<0.0001$ (results of the $t$ and Chi-square tests).

demographic attributes, had minimal influence on adherence. Multivariate analysis endorsed the contribution of some of these correlates in determining adherence including caregivers' and patients' knowledge of the illness, impaired insight, patients' attitudes, and their treatment satisfaction.

\section{Agreement between Adherence Measures}

The correlation coefficients in - Table $\mathbf{3}$ showed significant but modest correlations between the MAQ and the DAI-10 $(r=0.21-0.44)$ and between the MAQ and the CRS $(r=0.48$ 0.58 ). Multivariate analysis showed that $20 \%$ of the variance in the DAI-10 scores was explained by the MAQ scores. The DAI-10 was also significantly associated with the amounts of mood stabilizers consumed, but the strength of this correlation was weak $(r=0.27)$ and explained only $4 \%$ of the variance in mood stabilizers consumed. However, according to kappa values, the levels of agreement between different measures were poor for all estimations of concordance.

\section{Discussion}

\section{Comparisons with Other Studies}

This study focused on finding simple, low cost but fairly reliable methods to detect nonadherence in outpatients with BD from clinical settings. Among all the methods examined, the MAQ proved to be most suitable in this regard. It generated the maximum rate of poor adherence that was similar to other studies of the MAQ in BD (average rates of 50\%; range: $27-78 \%$ ). ${ }^{23-27}$ Moreover, similar to earlier studies, ${ }^{22,23}$ the MAQ also demonstrated satisfactory ability to detect both adherence and nonadherence in this study. Additionally, it displayed modest correlations with the CRS and the DAI-10. This reiterated the association of the MAQ with the DAI and many other subjective adherence measures in BD. ${ }^{23,28,29}$ Lastly, the MAQ demonstrated significant associations with several established determinants of nonadherence in BD including impaired insight and unawareness among patients, ${ }^{1,30}$ inadequate knowledge among 
Table 2 Adherence rates and psychometric properties of adherence measures

\begin{tabular}{|c|c|c|c|c|c|c|c|c|c|c|}
\hline & & & & & & \multicolumn{3}{|c|}{ Baseline assessment $(n=106)$} & \multicolumn{2}{|c|}{$\begin{array}{l}\text { Final } \\
\text { assessment } \\
(n=75)\end{array}$} \\
\hline \multicolumn{6}{|l|}{ MAQ scores } & \multicolumn{3}{|l|}{$0.84(1.2)^{\mathrm{a}}$} & \multicolumn{2}{|c|}{$1.06(1.4)$} \\
\hline \multicolumn{11}{|l|}{ MAQ categories } \\
\hline \multicolumn{6}{|c|}{ Adherent (scores of 3,4 ) } & \multicolumn{3}{|l|}{$53 \%$} & \multicolumn{2}{|l|}{$60 \%$} \\
\hline \multicolumn{6}{|c|}{ Nonadherent (scores of $0-2$ ) } & \multicolumn{3}{|l|}{$47 \%$} & \multicolumn{2}{|l|}{$40 \%$} \\
\hline \multicolumn{6}{|l|}{ CRS scores } & \multicolumn{3}{|l|}{$6.29(0.9)$} & \multicolumn{2}{|c|}{$6.3(0.8)$} \\
\hline \multicolumn{11}{|l|}{ CRS categories } \\
\hline \multicolumn{6}{|c|}{ Adherent (scores $\geq 5$ ) } & \multicolumn{3}{|l|}{$89 \%$} & \multicolumn{2}{|l|}{$96 \%$} \\
\hline \multicolumn{6}{|c|}{ Nonadherent (scores $\leq 4$ ) } & \multicolumn{3}{|l|}{$11 \%$} & \multicolumn{2}{|l|}{$4 \%$} \\
\hline \multicolumn{6}{|l|}{ DAl-10 scores } & \multicolumn{3}{|l|}{$2.9(1.8)$} & \multicolumn{2}{|l|}{$2.7(1.8)$} \\
\hline \multicolumn{11}{|c|}{ DAl-10 categories with cut-off at 0} \\
\hline \multicolumn{6}{|c|}{ Adherent (scores $>0$ ) } & \multicolumn{3}{|l|}{$91 \%$} & $96 \%$ & \\
\hline Nonadheren & (scores $\leq$ & & & & & $9 \%$ & & & $4 \%$ & \\
\hline DAl-10 categor & es with $\mathrm{Cl}$ & -off at 2 & & & & & & & & \\
\hline Adherent (sc & res > 2) & & & & & $65 \%$ & & & $65 \%$ & \\
\hline Nonadheren & (scores $\leq$ & & & & & $35 \%$ & & & $35 \%$ & \\
\hline $\begin{array}{l}\text { Proportion of } \\
\text { consumed acc }\end{array}$ & $\begin{array}{l}\text { I medicat } \\
\text { rding to } p\end{array}$ & $\begin{array}{l}\text { ons } \\
\text { II counts }\end{array}$ & & & & $98 \%$ & & & $97 \%$ & \\
\hline Adherence acc & rding to $\mathrm{F}$ & II counts & & & & & & & & \\
\hline Adherent & & & & & & $90 \%$ & & & $92 \%$ & \\
\hline Nonadheren & & & & & & $10 \%$ & & & $8 \%$ & \\
\hline Adherence acc & rding to $r$ & ood-stabi & zer les & & & $n=88$ & & & $n=65$ & \\
\hline Adherent & & & & & & $91 \%$ & & & $92 \%$ & \\
\hline Nonadheren & & & & & & $9 \%$ & & & $8 \%$ & \\
\hline Baseline asses & nent $^{\mathrm{b}, \mathrm{c}}$ & & & & & Final assessm & $n t^{b, c}$ & & & \\
\hline & $\begin{array}{l}\text { DAl-10 } \\
\text { (cut-off } \\
\text { at } 0 \text { ) }\end{array}$ & $\begin{array}{l}\text { DAl-10 } \\
\text { (cut-off } \\
\text { at 2) }\end{array}$ & CRS & Pill counts & $\begin{array}{l}\text { Serum } \\
\text { levels }\end{array}$ & $\begin{array}{l}\text { DAl-10 } \\
\text { (cut-off at } 0 \text { ) }\end{array}$ & $\begin{array}{l}\text { DAl-10 } \\
\text { (cut-off at 2) }\end{array}$ & CRS & $\begin{array}{l}\text { Pill } \\
\text { counts }\end{array}$ & $\begin{array}{l}\text { Serum } \\
\text { levels }\end{array}$ \\
\hline Sensitivity (\%) & 85 & 60 & 82 & 84 & 87 & 94 & 63 & 94 & 88 & 90 \\
\hline Specificity (\%) & 34 & 42 & 35 & 35 & 38 & 29 & 38 & 29 & 30 & 33 \\
\hline PPV (\%) & 37 & 45 & 37 & 37 & 41 & 38 & 48 & 39 & 39 & 43 \\
\hline NPV (\%) & 83 & 57 & 81 & 82 & 86 & 91 & 54 & 91 & 83 & 86 \\
\hline LR positive & 1.29 & 1.04 & 1.26 & 1.28 & 1.42 & 1.33 & 1.02 & 1.33 & 1.27 & 1.35 \\
\hline LR negative & 0.44 & 0.95 & 0.51 & 0.48 & 0.32 & 0.21 & 0.96 & 0.21 & 0.39 & 0.30 \\
\hline Accuracy (\%) & 50 & 50 & 50 & 50 & 55 & 50 & 50 & 50 & 50 & 54 \\
\hline
\end{tabular}

Abbreviations: CRS, Compliance Rating Scale; DAI-10, Drug Attitude Inventory,10-item version; LR, likelihood ratio; MAQ, Medication Adherence Questionnaire; NPV, negative predictive value; PPV, positive predictive value.

${ }^{a}$ Figures in brackets are standard deviations.

bProperties of the MAQ compared with composite non-adherence rates at both assessments: sensitivity (73\%), specificity (34-37\%), PPV (40-44\%), NPV (64-70\%), LR positive (1.10-1.16), LR negative (0.70-0.80), and classification accuracy (50\%).

'The MAQ was used as the reference standard for other measure.

caregivers, ${ }^{1}$ negative attitude of patients, as well as caregivers, ${ }^{30,31}$ and (to a lesser extent) severity of manic symptoms. ${ }^{1}$ These associations lent further validity to the use of the MAQ in ascertaining inadequate adherence in this disorder.
The rate of poor adherence was comparatively low using the DAI-10 with its traditional cut-off score of 0 . Three studies of nonadherence using the DAI-10 with the same cut-off score have reported low rates in $\mathrm{BD},{ }^{32-34}$ while one study reported a rate of $61 \%$, albeit among more severely ill 
18 Poor Adherence in Outpatients with Bipolar Disorder Chauhan et al.

Table 3 Correlates of measures of adherence: univariate analysis

\begin{tabular}{|c|c|c|}
\hline & $\begin{array}{l}\text { Baseline assessment } \\
(n=106)\end{array}$ & $\begin{array}{l}\text { Final assessment } \\
(n=75)\end{array}$ \\
\hline \multicolumn{3}{|l|}{ Correlates of $\mathrm{MAQ}^{\mathrm{a}}$} \\
\hline YMRS scores & $-0.24^{\mathrm{b}}$ & \\
\hline Unawareness (SUMD total scores) & $-0.23^{b}$ & $-0.24^{\mathrm{b}}$ \\
\hline Unawareness of social consequences of mental disorder & $-0.30^{\mathrm{b}}$ & $-0.30^{\mathrm{b}}$ \\
\hline Patients' knowledge of illness (total scores) & $0.33^{c}$ & $0.31^{\mathrm{c}}$ \\
\hline Patients' knowledge of diagnosis & $0.29^{b}$ & $0.24^{\mathrm{b}}$ \\
\hline Patients' knowledge of symptoms & $0.36^{c}$ & $0.31^{c}$ \\
\hline Patients' knowledge of treatment & & $0.25^{\mathrm{b}}$ \\
\hline DAI-10 & $0.21^{\mathrm{b}}$ & $0.44^{\mathrm{c}}$ \\
\hline CRS & $0.58^{d}$ & $0.48^{\mathrm{d}}$ \\
\hline Patients' attitudes (SRAQ total scores) & $0.24^{\mathrm{b}}$ & \\
\hline Caregivers' positive attitudes (SRAQ positive scores) & $0.23^{b}$ & \\
\hline Caregivers' knowledge of illness (total scores) & $0.29^{b}$ & $0.31^{c}$ \\
\hline Caregivers' knowledge of diagnosis & $0.23^{b}$ & \\
\hline Caregivers' knowledge of treatment & $0.31^{\mathrm{c}}$ & \\
\hline \multicolumn{3}{|l|}{ Correlates of $\mathrm{CRS}^{\mathrm{a}}$} \\
\hline Years of education & $0.23^{b}$ & $0.28^{\mathrm{b}}$ \\
\hline YMRS & $-0.31^{c}$ & \\
\hline Unawareness (SUMD total scores) & $-0.59^{d}$ & $-0.61^{d}$ \\
\hline Unawareness of mental disorder & $-0.47^{c}$ & $-0.47^{c}$ \\
\hline Unawareness of effects achieved by medication & $-0.59^{d}$ & $-0.61^{d}$ \\
\hline Unawareness of social consequences of mental disorder & $-0.52^{c}$ & $-0.54^{d}$ \\
\hline MAQ & $0.58^{d}$ & $0.48^{d}$ \\
\hline Patients' knowledge of illness (total scores) & $0.51^{\mathrm{c}}$ & $0.45^{c}$ \\
\hline Patients' knowledge of diagnosis & $0.35^{c}$ & $0.25^{b}$ \\
\hline Patients' knowledge of symptoms & $0.48^{c}$ & $0.42^{c}$ \\
\hline Patients' knowledge of causes & $0.33^{c}$ & $0.32^{c}$ \\
\hline Patients' knowledge of treatment & $0.48^{c}$ & $0.39^{c}$ \\
\hline Patients' knowledge of medications & $0.40^{c}$ & $0.33^{c}$ \\
\hline Caregivers' knowledge of illness (total scores) & $0.40^{c}$ & $0.34^{\mathrm{c}}$ \\
\hline Caregivers' knowledge of diagnosis & $0.31^{\mathrm{c}}$ & $0.32^{c}$ \\
\hline Caregivers' knowledge of causes & $0.25^{\mathrm{b}}$ & $0.25^{\mathrm{b}}$ \\
\hline Caregivers' knowledge of treatment & $0.33^{c}$ & $0.34^{c}$ \\
\hline Caregivers' knowledge of medications & $0.26^{\mathrm{b}}$ & $0.27^{b}$ \\
\hline \multicolumn{3}{|l|}{ Correlates of DAI- $10^{\mathrm{a}}$} \\
\hline Family income & $0.30^{c}$ & \\
\hline MAQ & $0.21^{b}$ & $0.44^{\mathrm{c}}$ \\
\hline Mood stabilizers consumed & $0.27^{b}$ & \\
\hline Patients' treatment-satisfaction & $0.27^{c}$ & $0.40^{c}$ \\
\hline \multicolumn{3}{|l|}{ Correlates of mood stabilizers consumed ${ }^{a}$} \\
\hline Unawareness (SUMD total scores) & $-0.37^{c}$ & \\
\hline Unawareness of effects achieved by medication & $-0.37^{c}$ & \\
\hline Unawareness of social consequences of mental disorder & $-0.39^{c}$ & \\
\hline
\end{tabular}


Table 3 (Continued)

\begin{tabular}{|c|c|c|}
\hline & $\begin{array}{l}\text { Baseline assessment } \\
(n=106)\end{array}$ & $\begin{array}{l}\text { Final assessment } \\
(n=75)\end{array}$ \\
\hline Patients' knowledge of illness (total scores) & $0.36^{c}$ & \\
\hline Patients' knowledge of symptoms & $0.45^{c}$ & $0.33^{c}$ \\
\hline Patients' knowledge of causes & $0.25^{\mathrm{b}}$ & \\
\hline Patients' knowledge of treatment & $0.32^{c}$ & \\
\hline DAI -10 & $0.27^{b}$ & \\
\hline Caregivers' positive attitudes (SRAQ positive scores) & $0.28^{b}$ & $0.25^{\mathrm{b}}$ \\
\hline Caregivers' knowledge of illness (total scores) & $0.37^{c}$ & $0.41^{\mathrm{c}}$ \\
\hline Caregivers' knowledge of diagnosis & $0.32^{c}$ & $0.34^{\mathrm{c}}$ \\
\hline Caregivers' knowledge of symptoms & $0.27^{b}$ & \\
\hline Caregivers' knowledge of treatment & $0.41^{\mathrm{c}}$ & $0.50^{c}$ \\
\hline Caregivers' knowledge of medications & $0.28^{\mathrm{b}}$ & $0.31^{\mathrm{c}}$ \\
\hline \multicolumn{3}{|l|}{ Correlates of antipsychotics consumed ${ }^{a}$} \\
\hline Patients' knowledge of symptoms & $0.34^{\mathrm{c}}$ & $0.41^{\mathrm{c}}$ \\
\hline Caregivers' knowledge of illness (total scores) & $0.34^{c}$ & $0.42^{c}$ \\
\hline Caregivers' knowledge of diagnosis & $0.34^{\mathrm{c}}$ & $0.37^{\mathrm{c}}$ \\
\hline Caregivers' knowledge of symptoms & $0.38^{c}$ & $0.38^{c}$ \\
\hline Caregivers' knowledge of treatment & & $0.41^{c}$ \\
\hline \multicolumn{3}{|l|}{ Correlates of mood-stabilizer levels ${ }^{a}$} \\
\hline Duration of illness & & $-0.32^{b}$ \\
\hline Number of all medications & $0.30^{\mathrm{b}}$ & \\
\hline Patients' attitudes (SRAQ total scores) & $0.38^{c}$ & $0.36^{\mathrm{c}}$ \\
\hline Patients' negative attitudes (SRAQ negative scores) & $0.35^{\mathrm{c}}$ & $0.34^{b}$ \\
\hline
\end{tabular}

Abbreviations: CRS, Compliance Rating Scale; DAI-10, Drug Attitude Inventory:10-item version; GAF, Global Assessment of Functioning scale; MAQ, Medication Adherence Questionnaire; SRAQ, Self Report Attitude Questionnaire; SUMD, Scale to Assess Unawareness of Mental Disorder; YMRS, Young Mania Rating Scale.

aPearson's or Spearman's coefficients.

${ }^{\mathrm{b}} p<0.05$.

${ }^{c} p<0.01$.

${ }^{\mathrm{d}} p<0.001$.

patients. ${ }^{35}$ Moreover, at this lower threshold, the DAI-10 was no better at detecting nonadherence than other measures. However, with a cut-off score of 2, the DAI-10 yielded nonadherence rates similar to the MAQ. Additionally, at this cutoff, the DAI-10 had the highest specificity and probability for detecting adherence, while its sensitivity for detecting nonadherence was only slightly lower than the other measures. These figures of sensitivity and specificity were comparable to other studies of BD employing higher cut-offs on the DAI$10 .{ }^{21}$ Lastly, the DAI-10 scores showed significant correlations with the MAQ scores and the amounts of mood stabilizers consumed, though the latter correlation was not very strong. This was similar to other studies of $B D$, where the DAI-10 has demonstrated significant associations with several other measures of adherence including the MAQ. ${ }^{21,28}$

Nonadherence rates derived from pill counts were lower than those based on self-reports in this study. Pill counts have usually produced lower rates (0-2\%) among outpatients with $\mathrm{BD}^{36}$ than among community-based patients
(39-63\%). ${ }^{8,10,37}$ Rates were lower in this study because patients/caregivers either failed to understand the procedure or forgot to bring the strips along. Outpatient-based pill counts are often unreliable because of these reasons, and because of the uncertainty about whether the tablets extracted are consumed. ${ }^{1,3,4}$ Consequently, many believe that pill counts are only useful if performed during unscheduled and unannounced home visits. ${ }^{3,8,37}$

Rates of nonadherence based on mood-stabilizer levels were similarly low in this study. However, such low rates were not entirely unexpected, because nonadherence based on mood-stabilizer levels has varied from 7 to $22 \%$ in most studies of $\mathrm{BD},{ }^{11,36,38}$ and 34 to $36 \%$ in others. ${ }^{5,7,9}$ Moreover, routine estimations of mood-stabilizer levels have several limitations. These include clinicians' dosing preferences, variable cut-offs to judge optimal adherence, individual variability, patients' tendency to take medications just before the tests, and their lack of cooperation. ${ }^{1,3-5}$ Therefore, it has been proposed that assessing the variability of levels in the same individual over 
Table 4 Correlates of measures of adherence: stepwise multiple regression analyses

\begin{tabular}{|c|c|c|c|c|c|}
\hline Baseline assessment & $R^{2}$ & Adjusted $R^{2}$ & Final assessment & $R^{2}$ & Adjusted $R^{2}$ \\
\hline \multicolumn{3}{|l|}{ MAQ } & \multicolumn{3}{|l|}{ MAQ } \\
\hline DAl & 0.20 & 0.19 & DAI & 0.20 & 0.19 \\
\hline $\begin{array}{l}\text { DAl, caregivers' knowledge } \\
\text { of treatment }\end{array}$ & 0.32 & 0.30 & $\begin{array}{l}\text { DAI, caregivers' knowledge } \\
\text { of treatment }\end{array}$ & 0.34 & 0.32 \\
\hline $\begin{array}{l}\text { DAI, caregivers' knowledge } \\
\text { of treatment, patients' } \\
\text { attitudes (total SRAQ) }\end{array}$ & 0.37 & 0.34 & $\begin{array}{l}\text { DAI, caregivers' knowledge } \\
\text { of treatment, unawareness } \\
\text { of the social consequences }\end{array}$ & 0.38 & 0.36 \\
\hline $\begin{array}{l}\text { DAI, caregivers' knowledge } \\
\text { of treatment, patients' } \\
\text { attitudes (total SRAQ), } \\
\text { unawareness of social } \\
\text { consequences }\end{array}$ & 0.41 & 0.38 & & & \\
\hline \multicolumn{6}{|l|}{ CRS } \\
\hline Unawareness (total SUMD) & 0.35 & 0.34 & $\begin{array}{l}\text { Unawareness of effects of } \\
\text { medications }\end{array}$ & 0.38 & 0.37 \\
\hline \multirow[t]{2}{*}{$\begin{array}{l}\text { Unawareness, patients' } \\
\text { knowledge of symptoms }\end{array}$} & 0.41 & 0.40 & $\begin{array}{l}\text { Unawareness of effects of } \\
\text { medications, patients } \\
\text { knowledge of symptoms }\end{array}$ & 0.45 & 0.43 \\
\hline & & & $\begin{array}{l}\text { Unawareness of effects of } \\
\text { medications, patients } \\
\text { knowledge of symptoms, } \\
\text { years of education }\end{array}$ & 0.49 & 0.47 \\
\hline \multicolumn{6}{|l|}{ DAI-10 } \\
\hline Family income & 0.09 & 0.08 & MAQ & 0.20 & 0.19 \\
\hline $\begin{array}{l}\text { Family income, patients' } \\
\text { treatment satisfaction }\end{array}$ & 0.16 & 0.14 & $\begin{array}{l}\text { Caregivers' knowledge of } \\
\text { medications }\end{array}$ & 0.33 & 0.30 \\
\hline \multicolumn{6}{|l|}{ Mood stabilizers consumed } \\
\hline $\begin{array}{l}\text { Patients' knowledge of } \\
\text { symptoms }\end{array}$ & 0.20 & 0.19 & $\begin{array}{l}\text { Caregivers' knowledge of } \\
\text { treatment }\end{array}$ & 0.25 & 0.24 \\
\hline $\begin{array}{l}\text { Patients' knowledge of } \\
\text { symptoms, caregivers' } \\
\text { knowledge of treatment }\end{array}$ & 0.27 & 0.24 & & & \\
\hline $\begin{array}{l}\text { Patients' knowledge of } \\
\text { symptoms, caregivers' } \\
\text { knowledge of treatment, } \\
\text { DAI }\end{array}$ & 0.32 & 0.28 & & & \\
\hline \multicolumn{6}{|l|}{ Antipsychotics consumed } \\
\hline $\begin{array}{l}\text { Caregivers knowledge of } \\
\text { symptoms }\end{array}$ & 0.14 & 0.12 & $\begin{array}{l}\text { PANSS general } \\
\text { psychopathology }\end{array}$ & 0.39 & 0.34 \\
\hline \multicolumn{3}{|l|}{ Serum levels } & \multicolumn{3}{|l|}{ Serum levels: final assessment } \\
\hline $\begin{array}{l}\text { Patients' attitudes (total } \\
\text { SRAQ) }\end{array}$ & 0.14 & 0.12 & $\begin{array}{l}\text { Patients' negative attitudes } \\
\text { (negative SRAQ) }\end{array}$ & 0.34 & 0.12 \\
\hline $\begin{array}{l}\text { Patients' attitudes (total } \\
\text { SRAQ); number of } \\
\text { medications }\end{array}$ & 0.21 & 0.18 & & & \\
\hline
\end{tabular}

Abbreviations: CRS, Compliance Rating Scale; DAI-10, Drug Attitude Inventory:10-item version; GAF, Global Assessment of Functioning scale; MAQ, Medication Adherence Questionnaire; PANSS, Positive and Negative Syndrome Scale; SRAQ, Self Report Attitude Questionnaire; SUMD, Scale to Assess Unawareness of Mental Disorder.

time may be a better way of detecting nonadherence in BD., 3,7 Nevertheless, serum levels had high sensitivity for identifying nonadherence coupled with high NPVs and LR positive in this study. They also had moderate specificity for determining adherence, together with high PPVs and LR negative. More- over, their accuracy in distinguishing adherent from nonadherent patients was greater than the other measures. These attributes of mood-stabilizer levels were comparable to two key studies of outpatients with BD, comparing blood levels with other adherence measures. ${ }^{5,9}$ 
The CRS yielded the lowest rates for nonadherence. Rates of nonadherence using the CRS and other clinician-rating scales have usually been low in $\mathrm{BD},{ }^{1,5,25,39}$ confirming the well-known fact that clinicians are frequently unable to recognize nonadherence. ${ }^{1-4}$ Inadequate interviewing techniques, unawareness of patients' views, and failure to take into account information from other sources are the common reasons for this misjudgement. ${ }^{1,3,4,40}$ Nevertheless, the CRS had a high sensitivity to detect nonadherence and modest agreement with the MAQ in this study. This coincided with the findings of some studies of BD. ${ }^{5}$ This suggests that if clinicians collate information from self-reports and blood levels while judging adherence and create a nonjudgmental atmosphere that encourages patient disclosure, they may still have a role in detecting nonadherence in resourceconstrained outpatient clinics.

\section{Limitations}

The principal limitations of this study were that patients were from a single center and only mildly ill at intake. The sample size was relatively small and the follow-up period was short. Moreover, the relatively low nonadherence rate, early dropouts, and minimal variation in adherence over time indicated a selection bias in favor of adherent patients. Therefore, the findings cannot be readily generalized or considered conclusive unless confirmed by subsequent studies.

\section{Conclusion and Implications}

This study found that self-reports such as the MAQ and the DAI-10 that were the most efficient measures for the identification of inadequate adherence in outpatients with BD. Compared with the other methods, they had higher yield, better ability to detect adherence, and moderate correlations with the other measures. Other attributes of these scales, such as their brevity, ease of administration, wide applicability, suitability for low literacy populations, and ability to discern barriers to adherence, also make them fitting options for identifying nonadherence among patients with BD from clinical settings. ${ }^{3,4,22}$ Mood-stabilizer levels, despite their low yields also performed well in detecting nonadherence and distinguishing it from adherence. However, since none of the measures were perfect, combinations of self-reports and mood-stabilizer levels may maximize the chances of identifying nonadherence in BD. It has been proposed that sequential use of different measures may improve recognition of nonadherence among all patients including those with $\mathrm{BD} .^{5}$ Accordingly, initial screening is best performed using selfreports. Reports of nonadherence based on self-reports are usually reliable. However, if patients report that they are adherent, this may need confirmation by periodic assessments of mood-stabilizer levels.

\section{Ethical Approval}

The study was approved by the research and ethics committees of the institute of the Postgraduate Institu- tion of Medical Education and Research (PGIMER; memo no. 8194/PG/2Tg/11077). Written informed consent was obtained from all participants prior to intake and other ethical safeguards were also maintained during the study.

\section{Authors' Contributions}

All authors were involved in the design and approval of the study. N.C. conducted the assessments under supervision of S.C. and S.G. All authors were involved in analysis of the data and the preparation of this article. All authors have read and approved the final draft.

Funding

None.

Conflict of Interest

None declared.

\section{References}

1 Berk L, Hallam KT, Colom F, et al. Enhancing medication adherence in patients with bipolar disorder. Hum Psychopharmacol 2010;25(01):1-16

2 Leclerc E, Mansur RB, Brietzke E. Determinants of adherence to treatment in bipolar disorder: a comprehensive review. J Affect Disord 2013;149(1-3):247-252

3 Sajatovic M, Velligan DI, Weiden PJ, Valenstein MA, Ogedegbe G. Measurement of psychiatric treatment adherence. J Psychosom Res 2010;69(06):591-599

4 Velligan DI, Weiden PJ, Sajatovic M, et al. Assessment of adherence problems in patients with serious and persistent mental illness: recommendations from the Expert Consensus Guidelines. J Psychiatr Pract 2010;16(01):34-45

5 Jónsdóttir $\mathrm{H}$, Opjordsmoen S, Birkenaes AB, et al. Medication adherence in outpatients with severe mental disorders: relation between self reports and serum level. Acta Psychiatr Scand 2013; 127:23-33

6 Lam WY, Fresco P. Medication adherence measures: an overview. BioMed Res Int 2015;2015:217047

7 Scott J, Pope M. Self-reported adherence to treatment with mood stabilizers, plasma levels, and psychiatric hospitalization. Am J Psychiatry 2002;159(11):1927-1929

8 Sajatovic M, Levin J, Tatsuoka C, et al. Customized adherence enhancement for individuals with bipolar disorder receiving antipsychotic therapy. Psychiatr Serv 2012;63(02):176-178

9 Scott J, Pope M. Nonadherence with mood stabilizers: prevalence and predictors. J Clin Psychiatry 2002;63(05):384-390

10 Pratt SI, Mueser KT, Driscoll M, Wolfe R, Bartels SJ. Medication nonadherence in older people with serious mental illness: prevalence and correlates. Psychiatr Rehabil J 2006;29(04):299-310

11 Rosa AR, Marco M, Fachel JM, Kapczinski F, Stein AT, Barros HM. Correlation between drug treatment adherence and lithium treatment attitudes and knowledge by bipolar patients. Prog Neuropsychopharmacol Biol Psychiatry 2007;31(01):217-224

12 Johnson DL. A Compendium of Psychosocial Measures. Assessment of People with Serious Mental Illnesses in the Community. New York, NY: Springer Publishing Company; 2010:1-584

13 Morisky DE, Green LW, Levine DM. Concurrent and predictive validity of a self-reported measure of medication adherence. Med Care 1986;24(01):67-74

14 Kemp R, Kirov G, Everitt B, Hayward P, David A. Randomised controlled trial of compliance therapy. 18-month follow-up. $\mathrm{Br} \mathrm{J}$ Psychiatry 1998;172:413-419

15 Awad AG. Subjective response to neuroleptics in schizophrenia. Schizophr Bull 1993;19(03):609-618 
16 Amador XF, Strauss DH, Yale SA, Flaum MM, Endicott J, Gorman JM. Assessment of insight in psychosis. Am J Psychiatry 1993;150 (06):873-879

17 Kotze C, King MP, Joubert PM. What do patients with psychotic and mood disorders know about their illness and medication? $\mathrm{S}$ Afr J Psychiatr 2008;14:84-90

18 Grover S, Chakrabarti S, Sharma A, Tyagi S. Attitudes toward psychotropic medications among patients with chronic psychiatric disorders and their family caregivers. J Neurosci Rural Pract 2014;5(04):374-383

19 Shipley K, Hilborn B, Hansell A, Tyrer J, Tyrer P. Patient satisfaction: a valid index of quality of care in a psychiatric service. Acta Psychiatr Scand 2000;101(04):330-333

20 Brain C, Allerby K, Sameby B, et al. Drug attitude and other predictors of medication adherence in schizophrenia: 12 months of electronic monitoring (MEMS) in the Swedish COAST-study. Eur Neuropsychopharmacol 2013;23(12):1754-1762

21 Shariati B, Shabani A, Ariana-Kia E, et al. Drug attitude inventory in patients with bipolar disorder: psychometric properties [in Portugese]. Iran J Psychiatry Behav Sci 2018;12:e9831

22 George CF, Peveler RC, Heiliger S, Thompson C. Compliance with tricyclic antidepressants: the value of four different methods of assessment. Br J Clin Pharmacol 2000;50(02):166-171

23 Copeland LA, Zeber JE, Salloum IM, Pincus HA, Fine MJ, Kilbourne AM. Treatment adherence and illness insight in veterans with bipolar disorder. J Nerv Ment Dis 2008;196(01):16-21

24 Miasso AI, do Carmo BP, Tirapelli CR. [Bipolar affective disorder: pharmacotherapeutic profile and adherence to medication]. Rev Esc Enferm USP 2012;46(03):689-695

25 De las Cuevas C, Peñate W, Sanz EJ. Psychiatric outpatients' selfreported adherence versus psychiatrists' impressions on adherence in affective disorders. Hum Psychopharmacol 2013;28(02):142-150

26 de Souza C, Vedana KG, Mercedes BP, Miasso AI. Bipolar disorder and medication: adherence, patients' knowledge and serum monitoring of lithium carbonate. Rev Lat Am Enfermagem 2013;21(02):624-631

27 Bahar G, Savas HA, Unal A, Bahar A. Treatment compliance of bipolar mood disorder patients and factors affecting compliance.J Mood Dis 2015;5:95-103

28 Thompson K, Kulkarni J, Sergejew AA. Reliability and validity of a new Medication Adherence Rating Scale (MARS) for the psychoses. Schizophr Res 2000;42(03):241-247

29 De Las Cuevas C, Peñate W. Psychometric properties of the eight-item Morisky Medication Adherence Scale (MMAS-8) in a psychiatric outpatient setting. Int J Clin Health Psychol 2015;15(02):121-129
30 García S, Martínez-Cengotitabengoa M, López-Zurbano S, et al. Adherence to antipsychotic medication in bipolar disorder and schizophrenic patients: a systematic review. J Clin Psychopharmacol 2016;36(04):355-371

31 Sajatovic M, DiBiasi F, Legacy SN. Attitudes toward antipsychotic treatment among patients with bipolar disorders and their clinicians: a systematic review. Neuropsychiatr Dis Treat 2017; 13:2285-2296

32 Medina E, Salvà J, Ampudia R, Maurino J, Larumbe J. Short-term clinical stability and lack of insight are associated with a negative attitude towards antipsychotic treatment at discharge in patients with schizophrenia and bipolar disorder. Patient Prefer Adherence 2012;6:623-629

33 Hibdye G, Dessalegne Y, Debero N, Bekan L, Sintayehu M. Prevalence of drug non- adherence and associated factors among patients with bipolar disorder at outpatient unit of Amanuel Hospital, Addis Ababa, Ethiopia, 2013. J Psychiatry 2015;S1:003

34 Montes JM, Maurino J, de Dios C, Medina E. Suboptimal treatment adherence in bipolar disorder: impact on clinical outcomes and functioning. Patient Prefer Adherence 2013;7:89-94

35 Ghaffari-Nejad A, Mashayekhi A, Mazhari S, Ghayoumi A. Factors associated with drug non-adherence after discharge among patients with mood disorders hospitalized in Shahid Beheshti Hospital in Kerman: a prospective study. Zahedan J Res Med Sci 2015;17:e968

36 Drotar D, Greenley RN, Demeter CA, et al. Adherence to pharmacological treatment for juvenile bipolar disorder. J Am Acad Child Adolesc Psychiatry 2007;46(07):831-839

37 Sajatovic M, Levin J, Tatsuoka C, et al. Six-month outcomes of customized adherence enhancement (CAE) therapy in bipolar disorder. Bipolar Disord 2012;14(03):291-300

38 Lam DH, Watkins ER, Hayward P, et al. A randomized controlled study of cognitive therapy for relapse prevention for bipolar affective disorder: outcome of the first year. Arch Gen Psychiatry 2003;60(02):145-152

39 Fornaro M, De Berardis D, Iasevoli F, et al. Treatment adherence towards prescribed medications in bipolar-II acute depressed patients: relationship with cyclothymic temperament and "therapeutic sensation seeking" in response towards subjective intolerance to pain. J Affect Disord 2013;151(02):596-604

40 Vieta E, Azorin JM, Bauer M, et al. Psychiatrists' perceptions of potential reasons for non- and partial adherence to medication: results of a survey in bipolar disorder from eight European countries. J Affect Disord 2012;143(1-3):125-130 